\title{
LABYRINTH SEAL AIR FLOW INVESTIGATION AND MEASUREMENT DEVICE INTRODUCTION
}

\author{
Michal Čížek, Jan Pařez ${ }^{1}$ \\ 1 Center of Aviation and Space Research, Faculty of Mechanical Engineering, Czech \\ Technical University in Prague, Jugoslávských partyzánů 1580/30, 16000, Prague
}

\begin{abstract}
For good aircraft gas turbine performance, a proper function of labyrinth seals sealing between rotating shaft and stator is necessary. This article presents comparison of mass flow through a labyrinth seal calculated using analytical solution and CFD. A new design of labyrinth seal measurement device is presented and its function is investigated using CFD.
\end{abstract}

Keywords: labyrinth seal, mass flow, aircraft gas turbine, analytical and CFD calculation

\section{Introduction}

The labyrinth seals are used to prevent the air flow between parts which must not be connected together as e.g. by a piston ring. In the aircraft gas turbines, where the rotating speed is in average approx. 35000 $\mathrm{rpm}$, the piston rings are inapplicable. Modern aircraft gas turbine consists of compressor with high pressure ratio and high-pressure turbine [1]. The high-pressure turbine and if it is needed also low pressure turbine need to cool the hot parts i.e. the turbine dovetail, disk and the cavity between stator and rotor [2]. Scheme of cooling air flow is in Figure $1-$ it is an example of jet engine.

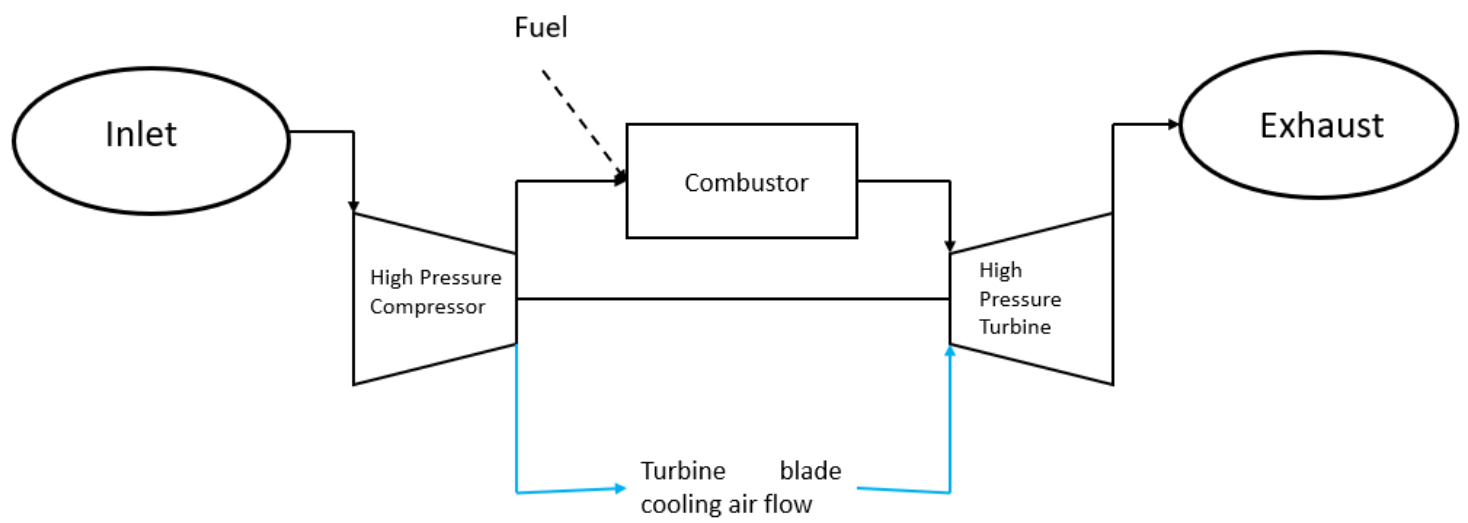

Figure 1: Cooling air flow in aircraft gas turbine

Due to the teeth, the pressure is decreasing. Key factor for control of the air flow in labyrinth seal is a radial clearance between the rotating and non-rotating parts (RC) [2] and [3]. When the $\mathrm{RC}$ is small, there is a high risk of accident. And when the RC is too high, the air flow there too high and sealing is not sufficient. Example whit RC variants and air flow investigation is in [4].

The analytical solution of mass flow through labyrinth seals was described in [2], [5], [6] and [7]. In [7] there are analytical calculations and CFD preliminary analysis of a measurement device. The measurement device that can be used for labyrinth seal measurement was introduced. In Center of Aviation and Space Research (CASR) at Faculty of mechanical Engineering of Czech Technical University in Prague (CTU), the new measurement device was designed and manufactured. In [8] the optical air flow measurement of labyrinth seal was described. The article [9] introduced the stepped labyrinth seal measurement device and discharge coefficient calculation. The comparison between CFD calculation and real aircraft gas turbine measurement are in [10] and [11].

This article aims to introduce the analytical mass flow calculation and labyrinth seal measurement test device of aircraft gas turbines. 


\section{Analytical mass flow calculation}

The Analytical air flow calculation through the labyrinth seal is complex and described in [5]. In this article only the important parts are used. The final mass flow is a function of flow coefficient $\varphi$. The $\varphi_{m}$ is flow coefficient in a specific tooth $\varphi_{m}$ :

$$
\varphi_{m}=f\left(\frac{p_{x}}{p_{0}}, x\right)
$$

where $p_{x}$ is pressure in specific teeth $[\mathrm{Pa}]$ and $p_{0}$ is inlet pressure [Pa]. The mass flow coefficient $\varphi$ is calculating by (2):

$$
\varphi=\sqrt{\frac{1-\left(\frac{p_{x}}{p_{0}}\right)^{2}}{m+\frac{3}{2 \cdot k} \cdot \ln \left(\frac{p_{0}}{p_{x}}\right)}},
$$

where $m$ is number of teeth and $k$ is an adiabatic exponent 1.4. The final mass flow is then calculated as:

$$
Q=A \cdot \varphi \cdot \frac{p_{0}}{\sqrt{r \cdot T_{0}}}
$$

where $A$ is area $\left[\mathrm{m}^{2}\right]$ and $r$ is specific gas constant $\left[\mathrm{J} \mathrm{kg}^{-1} \cdot \mathrm{K}^{-1}\right]$.

\section{Analytical and CFD calculations comparison}

For the 3D CFD calculations the labyrinth seal model from [11] was used. In short, it is isolated labyrinth seal with radial clearance $R C=0.1 \mathrm{~mm}$, rotational speed $n=60000 \mathrm{~min}^{-1}$, inlet pressure $p_{0}=300 \mathrm{kPa}$, inlet total temperature $T_{0}=288 \mathrm{~K}$ and turbulent model $\mathrm{k}-\varepsilon$. Two variable parameters were outlet pressure $p_{\text {out }}[\mathrm{Pa}]$ for simulating the pressure ratio $p_{x} / p_{0}$ (1) and number of teeth $m$. In simulations, 3, 4 and 5 teeth combinations were used.

Based on the equation (3), the analytical calculation was used. The comparison is in Figure 2.

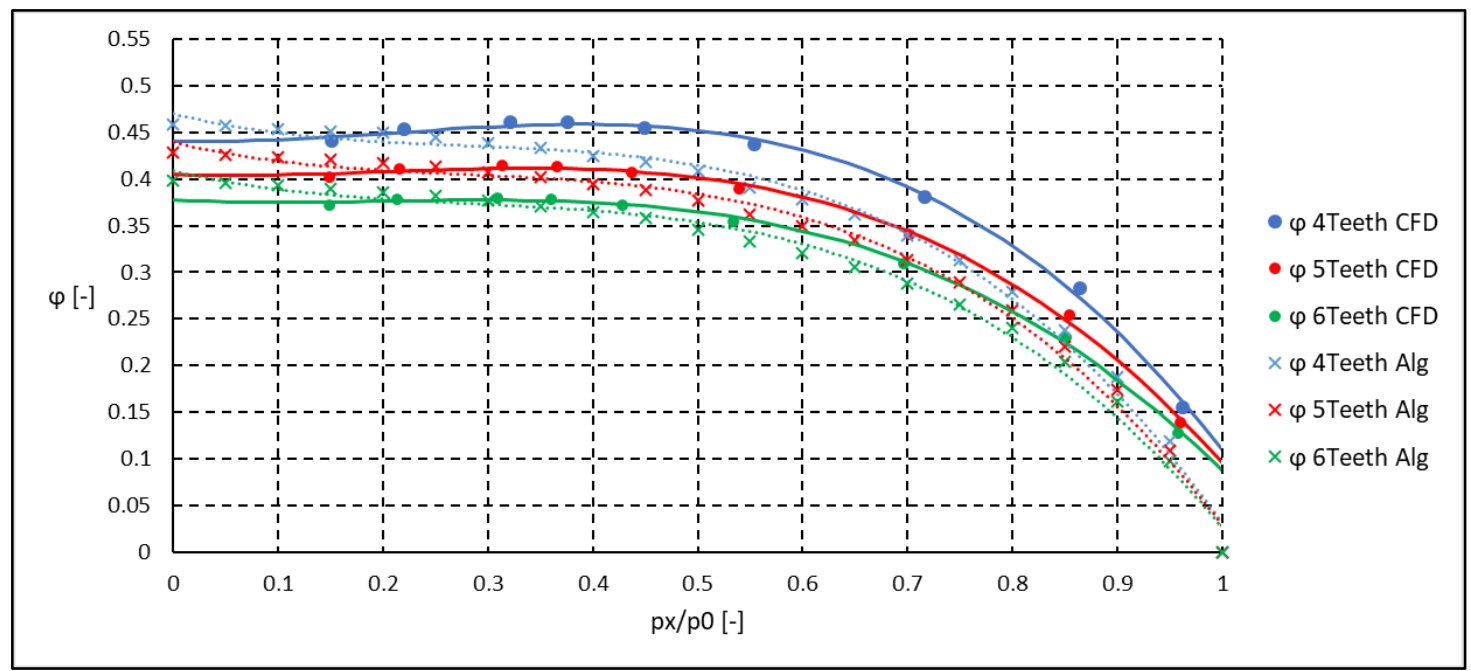

Figure 2: Analytical and CFD calculations comparison

In the chart, the flow coefficient $\varphi$ is on $\mathrm{Y}$ axis and pressure ratio on $\mathrm{X}$ axis. There are visible three variants of number of teeth. For each of variants there is a comparison between analytical and CFD calculations. Analytical (cross) are dashed lines and CFD (circle) are full lines. Interpolations by $3^{\text {rd }}$ degree polynomial were used. It is visible, that at pressure ratio equal to one, the mass flow is zero. All lines at this pressure ratio are close to zero. The differences between analytical and CFD calculations are:

1. The CFD consists of isolated domain with rotational periodic conditions

2. The analytical calculations are function of the area $A$ and pressure ratio $p_{x} / p_{0}$ 
Agreement between the analytical solution and CFD is good. The differences between analytical and CFD calculations with the same number of teeth at the same pressure ratio are less than 0.05 .

\section{Labyrinth seal measurement device}

Based on the previous researches ([4], [10] and [11]) it was decided to design new labyrinth seal measurement device in CASR. The reasons were two:

1. Better understanding of the thermodynamic problems in labyrinth seal

2. CFD model validation (because the previous models were evaluated in airplane gas turbine only) The device consists of three segments (see Figure 3 and test device in test stand is in Figure 4 - air inlet brass holes are visible in upper side):

1. Inlet domain -4 holes for pressure air inlet. Non-rotating domain

2. Labyrinths seal domain - rotating domain. Domain consist of 4 chamfered rectangles teeth which are in the Labyrinth Seal Disk. The disk is connected to the Rotating Shaft

3. Outlet domain - 4 holes for air outlet. Non-rotating domain

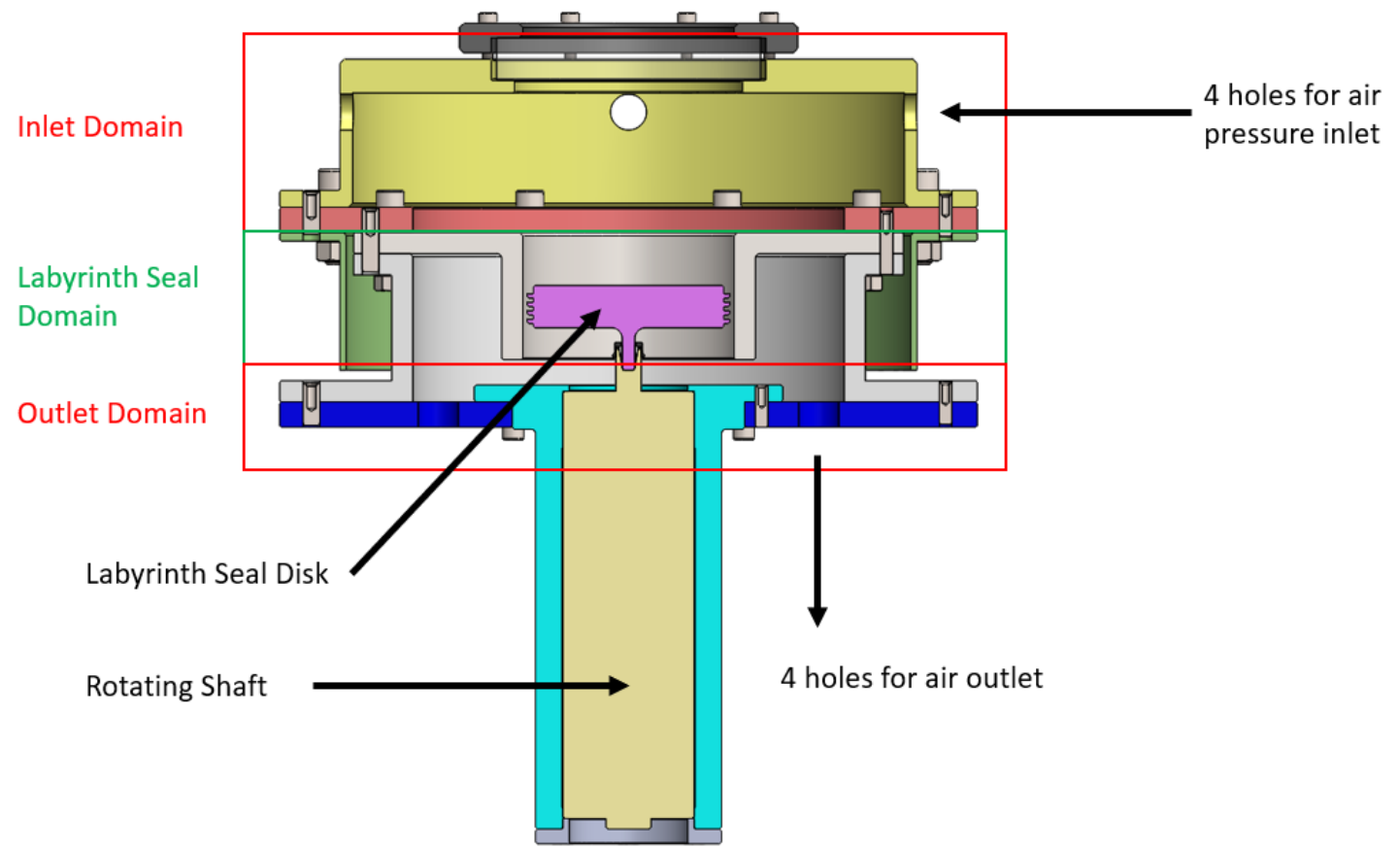

Figure 3: Measurement device calculation domains

All domains were created by NX v. 2012. The computational grids were created by ICEM CFD. The grid consists of 3.1M elements in Inlet Domain, 4M elements in Labyrinth Seal Domain and 3.7M elements in Outlet Domain. The grid incorporates the boundary layers on all walls. All boundary layers are resolved by 10 layers at minimum. The grid is in Figure 5 with labyrinth seal grid detail. The air flow is coming from upper 4 holes through the labyrinth seals to the 4 air outlet holes. The grid consists of hexahedral elements.

Boundary conditions for this calculation were set as:

- $R C=2 \mathrm{~mm}$

- $p_{0}=200000 \mathrm{~Pa}$

- $T_{0}=288 \mathrm{~K}$

- $p_{\text {out }}=101325 \mathrm{~Pa}$

- Shaft rotating velocity

The boundary conditions and setup for calculation were defined in CFX solver (see Figure 6). 


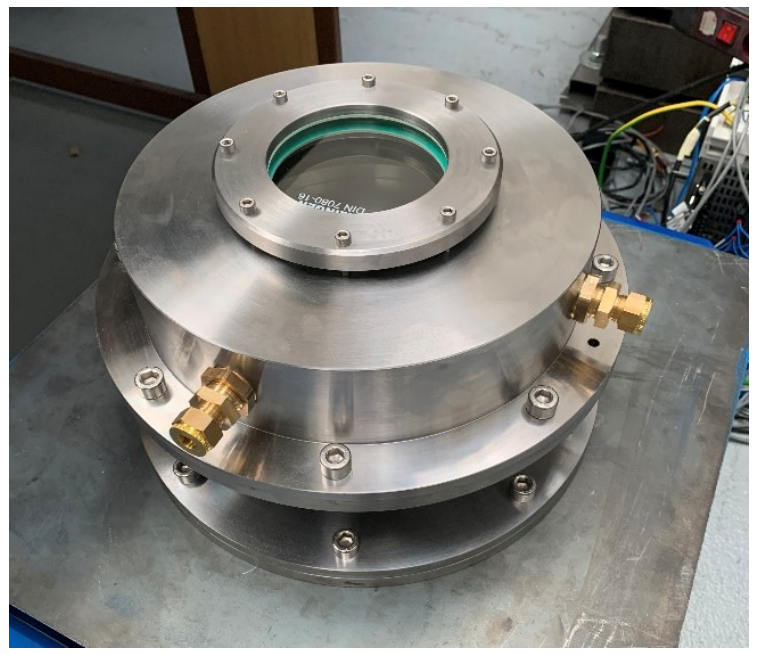

Figure 4: Test device in test stand

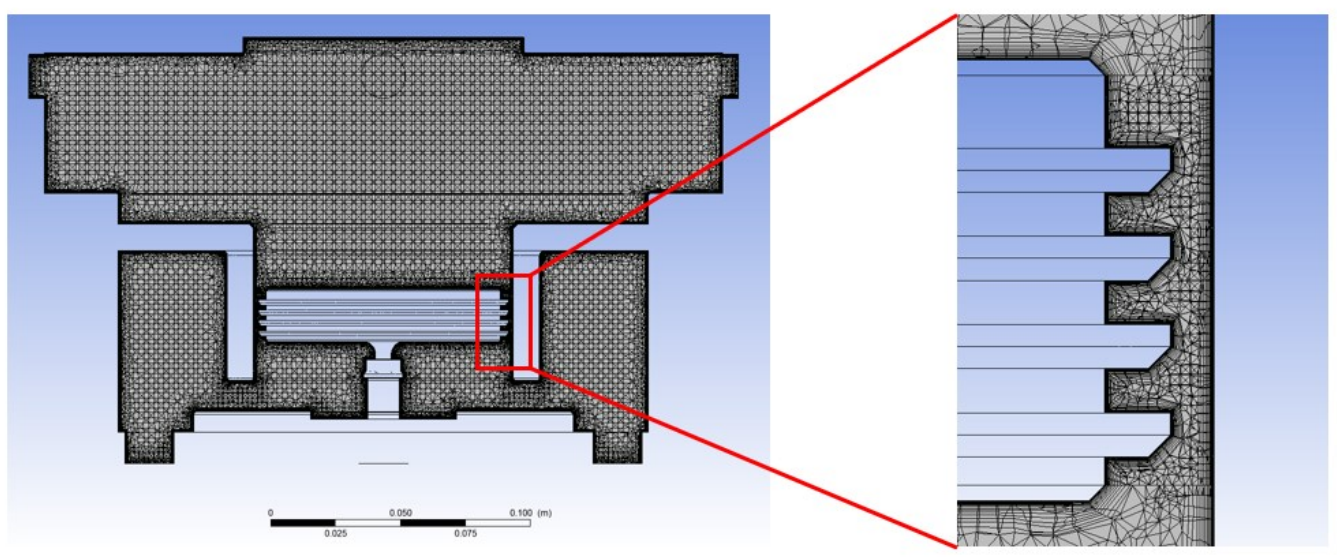

Figure 5: Calculation grid with labyrinth seal detail

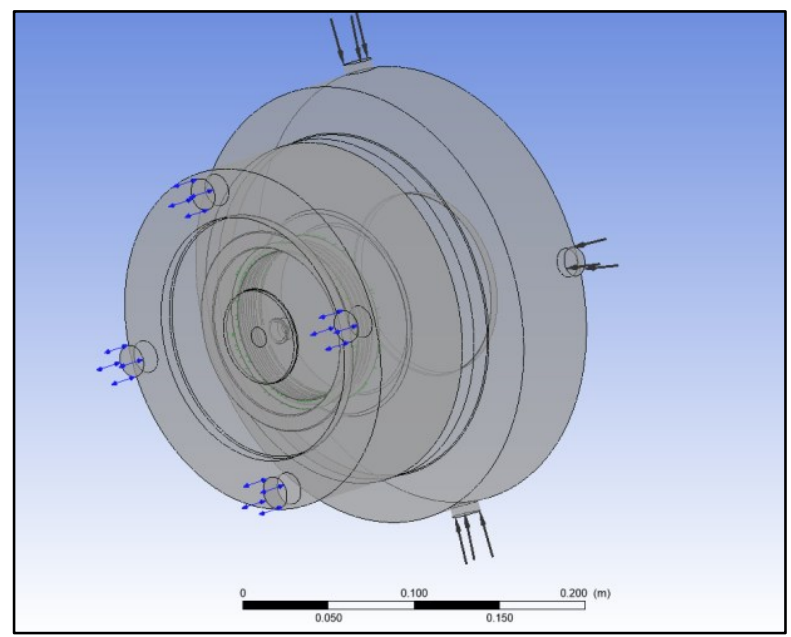

Figure 6: CFX boundary conditions definition

\section{Calculation}

Before running the test device, $10 \mathrm{CFD}$ calculations (result from paragraph 3 is, that is possible to use CFD) of test device were calculated. Based on the previous research (see [10]) the $\mathrm{k}-\varepsilon$ turbulent model was used. Residuals of the calculation less than 1E-03 were achieved - see Figure 7. The boundary conditions were the same with different rotating speed. In two planes, the performance parameters were 
plotted - labyrinth seal inlet plane (subscript inlet) and outlet plane (subscript outlet). In all of calculations, the static pressure, total temperature and mass flow were plotted and differences (eq. (4), (5) and (6)) between the inlet and outlet planes were calculated.

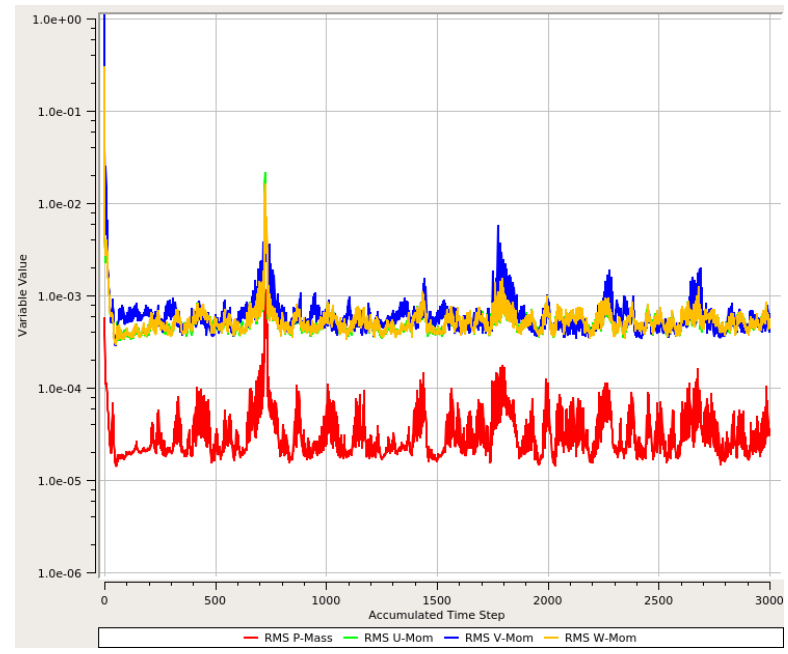

Figure 7: Calculation convergence

$$
\begin{aligned}
& \Delta p=p_{\text {outlet }}-p_{\text {inlet }}, \\
& \Delta T=T_{\text {outlet }}-T_{\text {inlet }}, \\
& Q p=Q_{\text {outlet }}-Q_{\text {inlet }},
\end{aligned}
$$

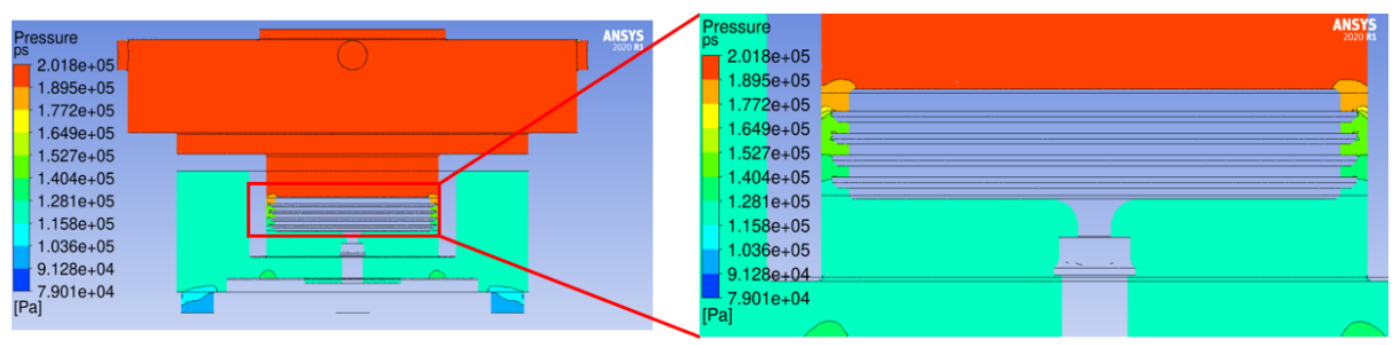

Figure 8: Static pressure with Labyrinth seal detail

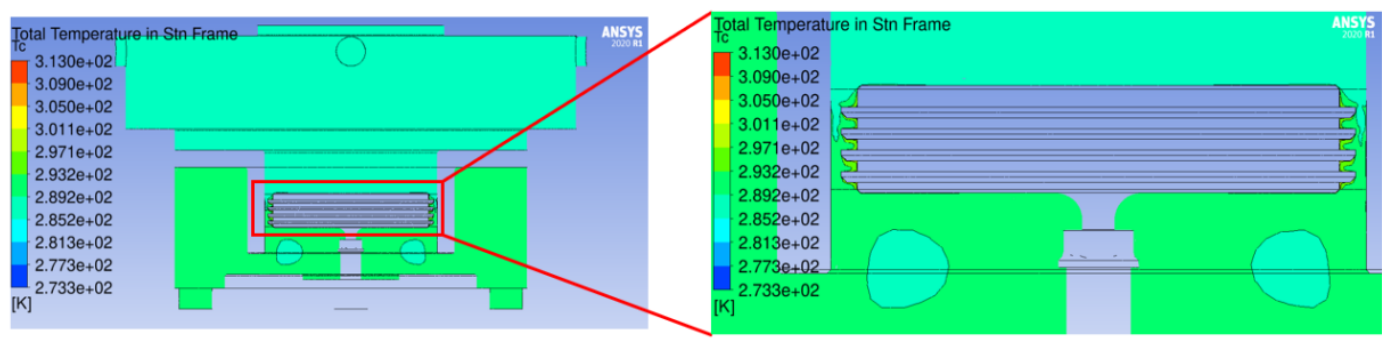

Figure 9: Total temperature distribution in the labyrinth seal (detail)

Figure 8 shows static pressure distribution at rotating speed $n=35000 \mathrm{~min}^{-1}$. It is possible to see, that the static pressure is decreasing through the teeth. In the inlet domain the pressure is constant. Pressure decrease past the teeth is well visible in the detail. It means, that the labyrinth seal is working correctly although the radial clearance $R C=2 \mathrm{~mm}$ is quite high (this value in aircraft gas turbine is not preferred better value is less than $0.5 \mathrm{~mm}[2])$. 
In Figure 9, total temperature distribution at rotating speed $n=35000 \mathrm{~min}^{-1}$ is presented. In the device the total temperature is approx. the same. In outlet domain the temperature is higher than in inlet domain, because technical work is being done on the flow by the rotating seal.

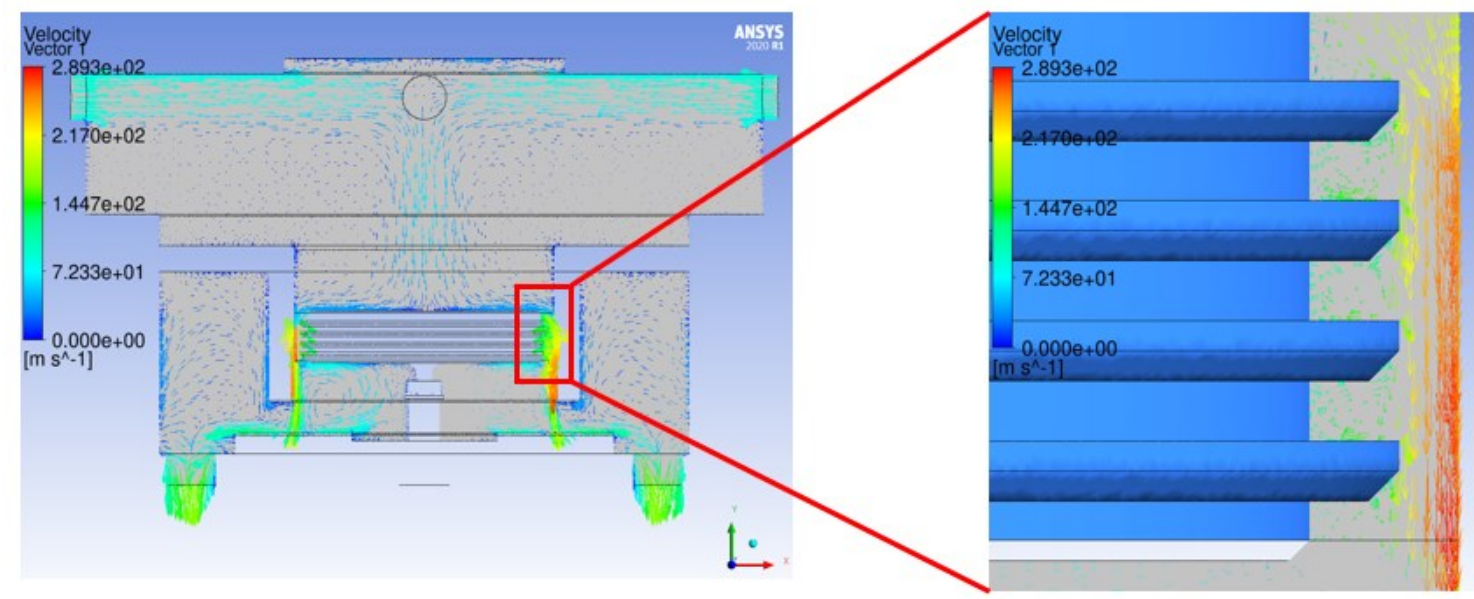

Figure 10: Velocity vectors with Labyrinth seal detail

In Figure 10, there are shown velocity vectors at rotating speed $n=35000 \mathrm{~min}^{-1}$. The flow is coming from the inlet holes to the seal. And in the labyrinth teeth the vortices are created (it is possible to see this from the detail). If the $R C$ is lower, vortices are more intensive.

Dependence of static pressure and total temperature differences (4) and (5) on rotating speed is shown in Figure 11. Static pressure differences are small, because inlet pressure $p_{0}$ and outlet pressure $p_{\text {out }}$ are the same at all of speeds and the difference is pressure loss. The total temperature difference is increasing with increasing rotational speed. The maximal difference between inlet and outlet temperature is approx.5.5 K. The value is not corresponding to that found in [11], where the temperature measurement was presented, because the $\mathrm{RC}$ is not comparable with previous researches.

Figure 12 provides mass flow characteristic. Because there are no blades, the flow is a function of the pressure at inlet, outlet and critical area. The mass flow is approx. constant across all speeds.

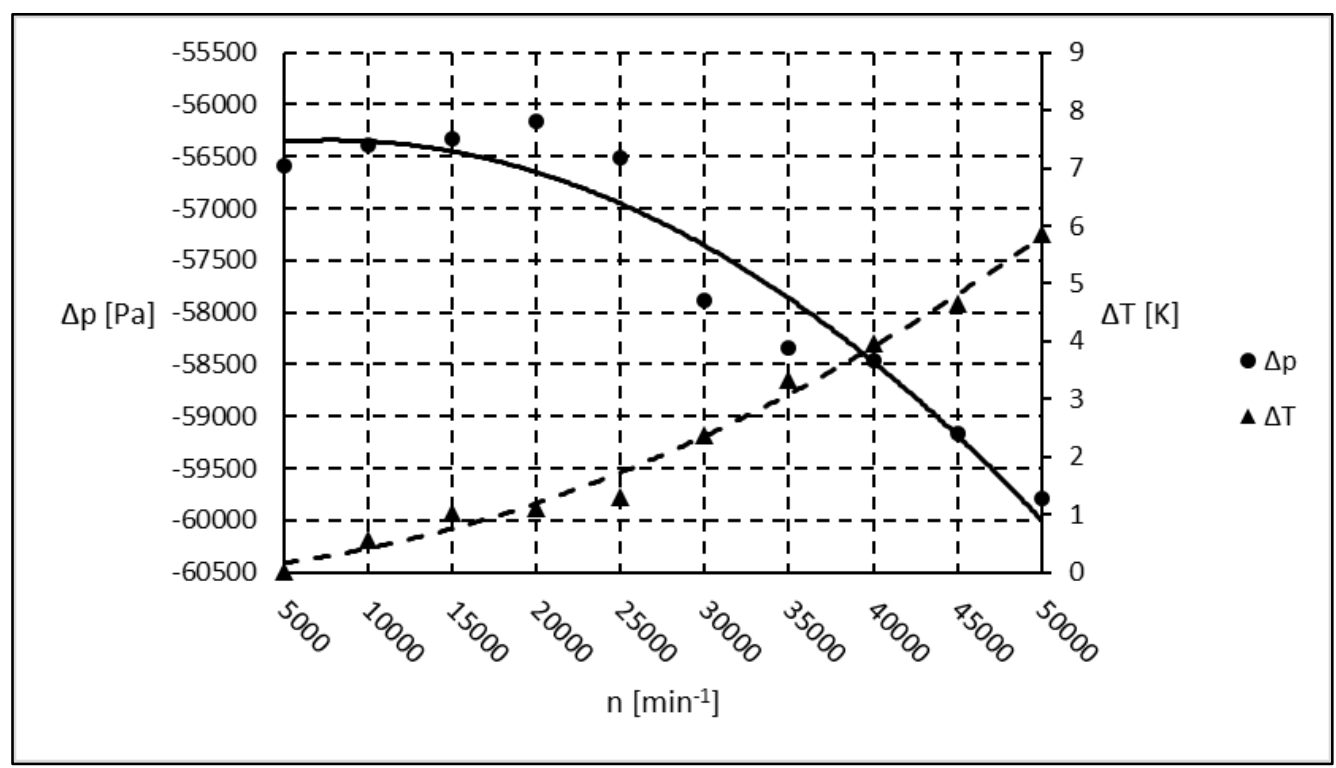

Figure 11: Static pressure and total temperature characteristic 


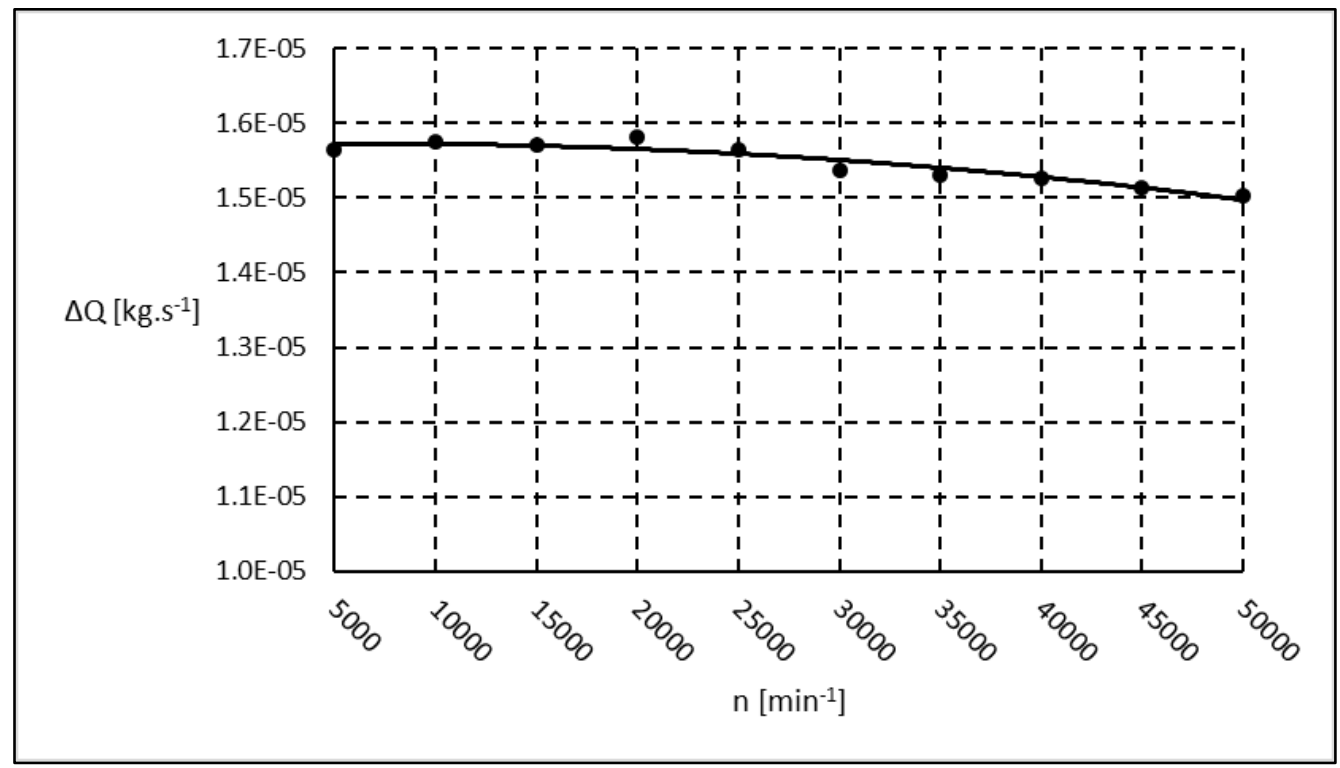

Figure 12: Mass flow characteristic

\section{Conclusion}

In this paper the analytical mass flow calculation was presented and compared with CFD calculation. The comparison (Figure 2) indicates that the flow coefficients, defined by (2), are similar when the analytical or CFD methods were used. Result of the comparison is that the CFD method is applicable in labyrinth seal calculation.

As a next step, the new labyrinth seal measurement device was described. For the CFD simulations, the device was divided to three domains. Inlet, labyrinth seal and outlet domain. Inlet and outlet domains are static. Labyrinth seal domain is rotating with angular velocity $n$. The labyrinth seal domain is representing the 4 labyrinth teeth with radial clearance $R C=2 \mathrm{~mm}$. Totally $10 \mathrm{CFD}$ calculations were done. The mass flow and static pressures are approx. constant across various rotational speeds. The total temperature increased with higher rotational speed. This is similar result like in [4].

Calculated data will be validated by measurements.

\section{Acknowledgment}

Authors acknowledge support from the ESIF, EU Operational Programme Research, Development and Education, and from the Center of Advanced Aerospace Technology (CZ.02.1.01/0.0/0.0/16_019/0000826), Faculty of Mechanical Engineering, Czech Technical University in Prague.

\section{References}

[1] Kurzke J., Halliwell I.: Propulsion and Power, Springer Internationally Publishing, ISBN: 978-3319-75977-7, (2018) pp. 687-696, doi: 10.1007/978-3-319-75979-1

[2] Sultanian B. K.: Gas turbine: Internal flow systems modelling, Cambridge University Press, ISBN: 978-110-7170-094, (2018) pp. 237-256

[3] Han Je-Chin, Dutta Sandip, Ekkad Srinath: Gas Turbine, Heat Transfer and Cooling Technology. CRC Press, ISBN: 978-1-4665-6490-9, (2013) pp. 1-26

[4] Č́žžek M., Pátek Z.: On CFD Investigation of Radial Clearance of Labyrinth Seals of a Turbine Engine, Acta Polytechnica, vol. 60, no. 1: (2020), pp. 38-48, doi: 10.14311/AP.2020.60.0038

[5] Jerie J., Teorie motorů, Ediční středisko ČVUT Praha 1, ISBN: 80-01-01460-6 (1996), pp. 332348

[6] Miškovský L.: Parní a plynové turbiny, 1.díl, Ústav parních motorů a kompresorů, (1937) 
[7] Enache M., Carlanescu R., Mangra A., Lorean F., Kuncser R.: Investigation of Flow through a Labyrinth Seal, INCAS Bulletin, vol. 13, no. 2: (2021), pp. 51-58, doi: 10.13111/20668201.2021.13.2.6

[8] Stoff H.: Incompressible flow in a labyrinth seal, Journal of Fluid Mechanics, vol. 100, no.5: (1980), pp. 817-829, doi: 10.1017/S0022112080001437

[9] Denecke J., Schramm V., Kim S., Wittig S.: Influence of Rub-Grooves on Labyrinth Seal Leakage, Turbo Expo 2002, vol. 3: (2002), doi: 10.1115/gt2002-30244

[10] Č́žžek M., Vampola T.: Labyrinth Seal of Aircraft Turbine Engine Air Flow Calculation at High Viscosity, Acta Mechanica Slovaca, vol. 23, no. 4: (2019), pp. 6-12, doi: 10.21496/ams.2020.011

[11] Č́ižek M., Vampola T., Popelka L.: Comparison of Labyrinth Seal Calculation and Real Aircraft Turbine Engine Measurement, Topical Problem of Fluid Mechanics 2020, ISBN: 978-80-8701274-1, (2020), pp. 19-26, doi: 10.14311/TPFM.2020.003 